\title{
Deafness due to bilateral endolymphatic sac tumours in a case of von Hippel-Lindau syndrome
}

\author{
G Kempermann, H P H Neumann, R Scheremet, B Volk, W Mann, J Gilsbach, R Laszig
} Freiburg i Br, Germany

Neurozentrum, Department of Neuropathology G Kempermann B Volk

Department of Nephrology and Hypertension H P H Neumann

Department of Otolaryngology R Laszig

Neurozentrum, Department of Neurosurgery R Scheremet

Department of Otolaryngology, Universitätsklinik Mainz, Germany W Mann

Department of Neurosurgery, Klinikum der RWTH, Germany J Gilsbach

Correspondence to: Dr Gerd Kempermann The Salk Institute for Biological Studies, Laboratory of Genetics, 10010 N Torrey Pines Road La Jolla, CA 92037, USA.

Received 1 August 1995 and in revised form Accepted 9 April 1996

(F Neurol Neurosurg Psychiatry 1996;61:318-320)

Keywords: inner ear; thyroid carcinoma

Most physicians think that von Hippel-Lindau syndrome is the rare, autosomal dominant coincidence of angiomatosis retinae and cerebellar hemangioblastoma. ${ }^{1}$ In reality, however, only $20 \%$ of patients with the disease show this combination, and with a prevalence of 1:40 000 the syndrome is much less rare than commonly thought. ${ }^{2}$ Other associated lesions include pheochromocytoma, pancreatic and renal cysts, renal carcinoma, and cystadenoma of the epididymis. In patients with one of these manifestations, von Hippel-Lindau syndrome should be excluded because more than $50 \%$ of patients with the disease show only one lesion of the range. ${ }^{23}$ Genetically von Hippel-Lindau syndrome is characterised by mutations within the recently identified von Hippel-Lindau syndrome tumour suppressor gene 4 localised on the short arm of chromosome $3(3 \mathrm{p} 25-26) .^{5}$ The diagnosis of von Hippel-Lindau syndrome is initially based on clinical findings of associated lesions in the patient and his close relatives; it can be confirmed by genetic analysis. $^{4} 6$

In this report we present an unusual case of von Hippel-Lindau syndrome in which bilat-

\begin{abstract}
Albert-LudwigsUniversität, Universitätsklinik,

Abstract

A case of bilateral endolymphatic sac tumours is reported. In a patient with von Hippel-Lindau syndrome, tumour growth in the right cerebellopontine angle caused deafness. The tumour was removed and classified as a metastasis from a thyroid carcinoma. However, on thyroidectomy no primary neoplasm could be found. Eight years later a similar tumour was operated on in the left petrosal bone. Histological appearance, immunocytochemical findings, and the clinical context gave evidence that the tumours had to be reclassified as endolymphatic sac tumours-extremely rare entities. The report supports the hypothesis, suggested by the few earlier case reports, that endolymphatic sac tumours could be one of the inherent tumour manifestations in von Hippel-Lindau syndrome.
\end{abstract}

eral tumour growth in the temporal or petrous bones caused deafness. Could tumours of the endolymphatic sac be one of the characteristic manifestations of the syndrome?

\section{Case report}

A patient, now 40 years old, with clinically confirmed von Hippel-Lindau syndrome and manifestation of cerebellar hemangioblastoma, angiomatosis retinae, renal cysts, and a hepatic angioma, developed severe hearing problems. In 1984 she was operated on because of a tumour of the right temporal bone.

Histologically, the diagnosis "metastasis of a follicular thyroid carcinoma" was made although no primary tumour was known. The tumour did not react with antibodies against thyreoglobulin and a metastasis into the temporal bone is unusual. Nevertheless, the histological appearance of the tumour (figure) suggested the diagnosis beyond reasonable doubt. However, no primary carcinoma could be detected after thyroidectomy a few weeks later. In 1992, eight years after thyroidectomy, the patient was operated on for a new tumour, now of the left temporal bone. Histopathologically, the tissue looked similar to the specimen from 1984, but it was much more solid, papillary structures were more prominent, and there were only occasional cysts filled with colloid (figure). Several foci consisted of clear, vacuolated cells. Although the diagnosis was considered to be suspect, the tumour was interpreted as tissue from a second metastasis of the hypothetical thyroid carcinoma. In 1993 the patient received a cochlear implant resulting in an enormous improvement in her quality of life. Pathological reconsideration leads to the new differential diagnosis of endolymphatic sac tumours. Collectively, the histological appearance, immunohistochemical analysis, and clinical history allowed revision of the original diagnosis. The patient could be freed from the pending diagnosis of a metastatic cancer disease. Unexpectedly, molecular analysis of specimens from both tumours did not show the loss of heterozygosity of closely linked markers on chromosome 3p25-26 that is characteristic of neoplastic lesions associated with von Hippel-Lindau syndrome. (For methodological details see Neumann et al. ${ }^{7}$ ) A nega- 
Endolymphatic sac tumours mimicking metastases from thyroid carcinoma. (A) Colloid filled cysts in the first tumour in the right temporal bone, resembling a follicular thyroid carcinoma. (B) Papillary structures and clear "plant cell like" cells in the second tumour from the left temporal bone.

Scale bars $=100 \mu \mathrm{m}$. (A) Haematoxylin and eosin stain; (B) periodic acid-Schiff's stain
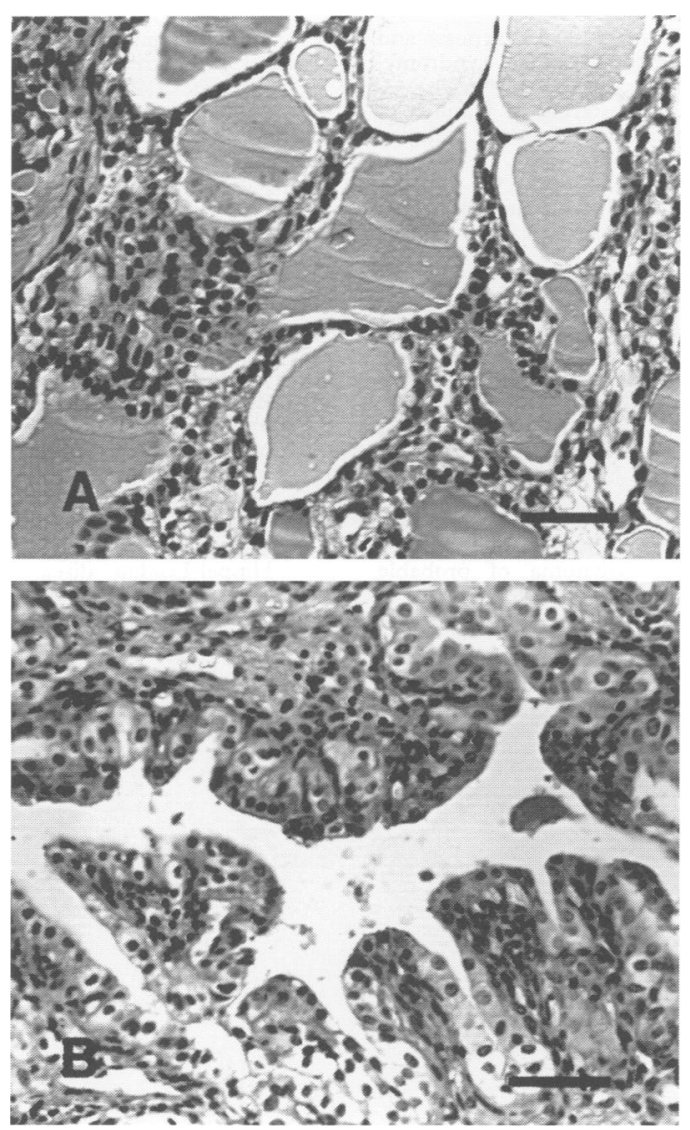

tive genetic analysis, however, is not exceptional in tumour tissues in cases of von Hippel-Lindau syndrome. ${ }^{?}$

\section{Discussion}

Endolymphatic sac tumours are adenomas originating from the epithelium of the endolymphatic sac of the inner ear. They are of neuroectodermal origin and seem to be extremely rare. Accordingly, the entity has not yet been well defined. Heffner reported 20 cases and listed the histological criteria ${ }^{8}$ which we followed to establish the new diagnosis in our patient. In most of Heffner's cases, the neoplasms had to be reclassified after a primary diagnosis had turned out to be questionable. The only case in which intraoperative evidence proved the origin of the tumour from the endolymphatic sac has been reported by Hassard and coworkers in $1984 .{ }^{9}$ In at least three cases the primary diagnosis of a metastatic thyroid tumour has been made. Other diagnoses included plexus papilloma, tumours of the ceruminal glands, bone cysts, so-called "glandular tumours of mixed histology", paragangliomas, metastases of renal carcinoma, and carcinomas that were not further specified. ${ }^{810}$

If recognised as primary tumours of the ear they have often been misinterpreted as (papillary) middle ear tumours. ${ }^{912}$ In most references endolymphatic sac tumours are referred to as adenomas or low grade adenocarcinomas, although they show little pleomorphism and only few mitotic profiles. Their growth is locally invasive but metastases have not been reported. The tumours have a papillary and cystic texture. The epithelium lining the cysts is uniform, single layered, and cuboidal. Its border to the stroma is often blurred and the papillary structures can be differentiated to a variable degree. The cystic lumina can be filled with a colloid that stains positive in the periodic acid Schiff's reaction and negative for mucicarmin and thus resemble thyroid follicles. In some cases there are areas with clear cells with a central nucleus; the cells resembling plant cells. Many tumours show fibrotic, haemorrhagic, and regressive aspects.

Immunohistochemically, the tumours stain positive for cytokeratin, often for glial fibrillary acidic protein, and negative for protein S100, synaptophysin, and thyroglobulin. ${ }^{9}$

In our patient these diagnostic criteria were fulfilled, the first tumour being extreme in terms of the number of colloid filled structures. Both tumours stained negative for glial fibrillary acidic protein, synaptophysin, and thyroglobulin, but positive for cytokeratin.

The bilateral appearance of an endolymphatic sac tumour strongly supports the hypothesis of a superordinate pathogenetic principle. It has been suspected that endolymphatic sac tumours could be another pathogenetically linked manifestation among the lesions of von Hippel-Lindau syndrome. In our patient, however, molecular proof of this assumption could not be found.

Poe and coworkers have reported two cases of bilateral tumours of the inner ear in patients with von Hippel-Lindau syndrome. ${ }^{11}$ There exist other reports (for more references see Lo et $a l^{12}$ ) of inner ear tumours in von HippelLindau syndrome. With the exception of that of Delisle et al, none of these explicitly mentions endolymphatic sac tumours. ${ }^{13}$ However, Gaffrey et al have reported seven cases of aggressive papillary tumours of the middle ear in patients with von Hippel-Lindau syndrome. ${ }^{14}$ As middle ear adenomas and aggressive papillary tumours of the middle ear are the most important differential diagnosis of endolymphatic sac tumours, ${ }^{1012}$ it remains to be examined which relation exists between these entities and tumours of the inner ear, particularly in cases of von Hippel-Lindau syndrome. Interestingly, already the first patient of von Hippel was found to have a tumour of the petrous bone that histologically resembled a metastasis (without a primary tumour) from a renal carcinoma. ${ }^{15} 16$

As endolymphatic sac tumours are difficult to detect and the diagnosis might often be missed because the entity is still unknown, we report this single case here. We hope that clinicians will review the records of their patients with proved or suspected von Hippel-Lindau syndrome for hearing problems and tumours of the temporal bone and report clinical or molecular evidence for or against the idea that endolymphatic sac tumours could be an associated lesion in von Hippel-Lindau syndrome.

We thank Bernhard Bender for the molecular analysis of the tumours and Philip Horner for comments on the manuscript. 
1 Neumann HPH. Basic criteria for clinical diagnosis and genetic counselling in von Hippel-Lindau syndrome. Vasa $\mathcal{F}$ Vasc Dis 1987;16:220-6.

2 Neumann HPH, Wiestler OD. Clustering of features of von Hippel-Lindau syndrome: evidence for a complex genetic locus. Lancet 1991;337:1052-4.

3 Neumann HPH, Berger P, Sigmund G, et al. Pheochromocytomas, multiple endocrine neoplasia type Pheochromocytomas, multiple endocrine neoplasia type
2, and von Hippel-Lindau disease. N Engl $\mathcal{F}$ Med

4 Latif F, Tory K, Gnarra J, et al. Identification of the von Hippel-Lindau disease tumor suppressor gene. Science 1993;260:1317-20.

5 Seizinger BR, Rouleau GA, Ozelius LJ, et al. Von HippelLindau disease maps to the region of chromosome 3 associated with renal carcinoma. Nature 1988;332:268-9.

6 Chen F, Kishida T, Yao M, et al. Germ line mutation in the von Hippel-Lindau disease tumor suppressor gene: correlations with phenotype. Human Mutations 1995;5:66-75

7 Neumann HPH, Lips CJM, Hsia YE, Zbar B. Von HippelLindau syndrome. Brain Pathology 1995;5:181-93.

8 Heffner DK. Low-grade adenocarcinoma of probable endolymphatic sac origin. Cancer 1989;64:2292-302.

9 Hassard AD, Boudreau SF, Cron CC. Adenoma of the endolymphatic sac. f Otolaryngol 1984;13:213-6.

$10 \mathrm{Li}$ JC, Brackmann DE, Lo WWM, Carberry JN, House JW. Reclassification of aggressive adenomatous mastoid neoplasms as endolymphatic sac tumors. Laryngoscope 1993;103:1342-8.

11 Poe DS, Tarlov EC, Thomas CB, Kveton JF. Aggressive papillary tumors of the temporal bone. Otolaryngol Head peck Surg 1993;108:80-6.

12 Lo WWM, Applegate LJ, Carberry JN, et al. Endolymphatic sac tumors: radiologic appearance. Radiology 1993;189:199-204.

13 Delisle MB, Uro E, Rouquette I, Yardeni E, Rumeau JL. Papillary neoplasm of the endolymphatic sac in a patient with von Hippel-Lindau disease. I Clin Pathol 1994;47:959-61.

14 Gaffey MJ, Mills SE, Boyd JC. Aggressive papillary tumor of middle ear/temporal bone and adnexal papillary cystadenoma. Am f Surg Pathol 1994;18:1254-60.

15 Brandt R. Zur Frage der Angiomatosis retinae. Graefes Arch Ophthalmol 1921;106:127-36.

16 Resche F, Moisan JP, Mantoura J, et al. Haemangioblastoma, haemangiobastomatosis and von Hippel-Lindau disease. Adv Techn Stand Neurosurg 1993;20:197-304. 